\title{
Delays in alternative tests defer animal ban
}

Utrecht. The introduction of a new European Union law banning the avoidable use of animals in toxicity tests for cosmetics is likely to be delayed until 2000 because no suitable alternative tests have been successfully developed.

Member states of the union had agreed to a European Commission directive that would have banned animal tests where alternative tests exist from 1998. But animal welfare groups and industrialists attending the second World Congress on Alternatives and Animal Use in the Life Sciences in Utrecht, the Netherlands, last week reluctantly agreed that animals will continue to be used for several years to come.

The congress heard that a significant step forward had been achieved, however, with the completion of the first attempt to produce international standards for validating alternative tests. A Practice without pain: an artificial rat which has been workshop run by the Organization for developed for training in microsurgical techniques. Economic Cooperation and Development (OECD) has looked at the harmonization of the acceptance criteria for alternative toxicological testing. Its report was presented at the congress for discussion and approval.

But the move probably comes too late to stop the commission from invoking a clause

in its directive that provides for a two-year delay in introducing the ban if no alternative tests have been validated by January 1997 . Internal commission documents indicate that it will recommend such a delay before the end of this year.

Alternative tests have proved difficult to

\section{IMAGE UNAVAILABLE FOR COPYRIGHT REASONS}

develop for two main reasons. First, scientists are hampered by the lack of strong data on animal tests currently used, because industry is reluctant, for commercial reasons, to make its files available to independent test developers. Industry is also reluctant to provide outsiders with the

\section{Energy labs link up genome efforts}

Washington. The US Department of Energy (DoE) is to consolidate its \$35-million-ayear gene-sequencing effort under a single organization, the Joint Genome Institute, which it says will sequence up to 40 per cent of the 3 billion base pairs in the human genome by 2005 .

Officials say the move is intended to be much more than a cosmetic change to DoE's gene-sequencing effort. It is seen as a muchneeded attempt by the department to regain the initiative in the US Human Genome Project, which originated in DoE laboratories in 1986 but is now 70 per cent funded by the National Institutes of Health (NIH).

The new institute will control sequencing work at the Lawrence Berkeley and Lawrence Livermore National Laboratories in California, and at the Los Alamos National Laboratory in New Mexico. Its director, Elbert Branscomb, formerly a senior scientist at Livermore, does not deny that the DoE has been falling behind the NIH and the private sector in sequencing the genome. "We became persuaded that, if we didn't do something, that would rapidly become the case," he says.

The institute will account for about half of the DoE's total effort under the Human Genome Project. Branscomb says that it will change the way in which the chemicals they need to validate new tests. Second, alternative tests have to prove equal to, or better than, animal tests, even though most animal tests have never been shown to be the best models of human toxicity. Using an endpoint achieved in a complex system like an animal, which may well be less than ideal, as a reference makes validation पे of alternative tests more difficult than it need be, argue campaigners.

In addition, the political climate has not supported, until recently, a concerted effort for the development of alternative methods. In the past few years, however, several institutions have been founded in different countries to support such efforts and validate new tests. The European Commission established its own centre, the European Centre for the Validation of Alternative Methods at Ispra, Italy, in 1991.

Steve McIvor, head of campaigns for the international cosmetics retailer Body Shop, whose products are not tested on animals, says that replacements are not in sight for the most commonly used toxicity tests - the guinea-pig skin-sensitization test, rabbit-eye irritancy test (the Draize test), and guinea-pig and rabbit skinirritancy tests.

Alternative-test developers have reached a dead end, he says. Along with other animal welfare campaigners, he believes regulators must accept that new methods should be developed from scratch, "without reference to existing animal tests which are both complex and of uncertain accuracy". Alternative-test developers are now also trying to acquire more human data from poison clinics, a source of information that has been insufficiently tapped, he says.

The Body Shop and other organizations are campaigning for a moratorium on the testing and introduction of new cosmetic ingredients until alternative tests are found. Industry is unlikely to agree. It is, however, just as interested as animal welfare campaigners in encouraging the development of alternative testing methods, which would be cheaper and easier to automate.

The number of animals used in cosmetics testing is not known because of difficulties in gathering reliable statistics. In Europe, figures have been published only for France and the United Kingdom. These are 20,000 (1993) and 3,500 (1994) respectively.

The OECD working group report is expected to be adopted into the organization's general toxicity testing guidelines. It may help to spread the high costs of running validation studies - large-scale blinded trials to prove the merit of alternative tests - by encouraging industry and regulatory agencies worldwide to cooperate with each other.

Alison Abbott 